\title{
Access to expert stroke care with telemedicine: REACH MUSC
}

\author{
Abby Swanson Kazley ${ }^{1}$, Rebecca C. Wilkerson ${ }^{2}$, Edward Jauch ${ }^{3}$ and Robert J. Adams ${ }^{4}$ * \\ ${ }^{1}$ Department of Health Care Leadership and Management, Medical University of South Carolina, Charleston, SC, USA \\ ${ }^{2}$ South Carolina Environmental Public Health Tracking Program, South Carolina Department of Health and Environmental Control, Columbia, SC, USA \\ ${ }^{3}$ Department of Emergency Medicine, Medical University of South Carolina, Charleston, SC, USA \\ ${ }^{4}$ Department of Neurosciences, Medical University of South Carolina, Charleston, SC, USA
}

\section{Edited by:}

Steven Levine, Mount Sinai School of Medicine, USA

Reviewed by:

Steven Rudolph, Miamonides Medical Center, USA

Kumar Rajamani, Wayne State

University, USA

${ }^{*}$ Correspondence:

Robert J. Adams, Department of Neurosciences, MUSC Stroke Center, Medical University of South Carolina, D19 Hagood Avenue, Suite 501, Charleston, SC 29425, USA.

e-mail: adamsri@musc.edu
Stroke is a leading cause of death and disability, and recombinant tissue plasminogen activator (rtPA) can significantly reduce the long-term impact of acute ischemic stroke (AIS) if given within $3 \mathrm{~h}$ of symptom onset. South Carolina is located in the "stroke belt" and has a high rate of stroke and stroke mortality. Many small rural SC hospitals do not maintain the expertise needed to treat AIS patients with rtPA. MUSC is an academic medical center using REACH MUSC telemedicine to deliver stroke care to 15 hospitals in the state, increasing the likelihood of timely treatment with rtPA. The purpose of this study is to determine the increase in access to rtPA through the use of telemedicine for AIS in the general population and in specific segments of the population based on age, gender, race, ethnicity, education, urban/rural residence, poverty, and stroke mortality. We used a retrospective cross-sectional design examining Census data from 2000 and geographic information systems analysis to identify South Carolina residents that live within 30 or 60 min of a primary stroke center (PSC) or a REACH MUSC site. We include all South Carolina citizens in our analysis and specifically examine the population's age, gender, race, ethnicity, education, urban/rural residence, poverty, and stroke mortality. Our sample includes 4,012,012 South Carolinians. The main measure is access to expert stroke care at a PSC or a REACH MUSC hospital within 30 or $60 \mathrm{~min}$. We find that without REACH MUSC, only $38 \%$ of the population has potential access to expert stroke care in SC within 60 min given that most PSCs will maintain expert stroke coverage. REACH MUSC allows $76 \%$ of the population to be within 60 min of expert stroke care, and $43 \%$ of the population to be within 30 min drive time of expert stroke care. These increases in access are especially significant for groups that have faced disparities in care and high rates of AIS. The use of telemedicine can greatly increase access to care for residents throughout South Carolina.

Keywords: access to care, rtPA, telestroke, reducing disparities in access

\section{INTRODUCTION}

Stroke is a leading cause of death and disability in the United States (Thom et al., 2006; Hoody et al., 2008). South Carolina has especially high stroke incidence and mortality rates, particularly in younger and African American patients when compared to the rest of the country. Because of this, South Carolina has been referred to as the epicenter of the "stroke belt." In fact, South Carolina has ranked among the highest in the country for stroke mortality (Lackland et al., 1998; Shrira et al., 2008).

In 1996, the Food and Drug Administration (FDA) approved the use of recombinant tissue plasminogen activator (rtPA), a fibrinolytic drug, for the treatment of acute ischemic stroke (AIS; O'Fallon et al., 2004). When administered appropriately, rtPA significantly reduces the long term disability and physical damage that can follow AIS (Alberts et al., 2000; Schwab et al., 2007). Although rtPA was the first FDA approved treatment for AIS, the use of rtPA has not become widespread in part because it must be administered within $3 \mathrm{~h}$ of the onset of stroke symptoms (Kleindorfer et al., 2004; Hacke et al., 2008; Meschia, 2009). Many hospitals lack the stroke expertise, resources, and protocols to successfully treat AIS with rtPA (Gropen et al., 2006). In fact, Capampangan et al. (2009) report that despite over a decade after FDA approval still fewer than $5 \%$ of AIS patients receive rtPA.

Current challenges related to geography and resource limitations can influence patient access to stroke care and rtPA (Wang et al., 2004; Saposnik et al., 2008). Nearly half (45\% or 135 million) of all Americans live more than $1 \mathrm{~h}$ away from "lifesaving stroke care" (Carr, 2010), and 40\% of the population in the United States lives in counties with hospitals that have given rtPA to less than $2.4 \%$ of AIS patients (Kleindorfer et al., 2009). Several groups, including the brain attack coalition (BAC) and the American Stroke Association (ASA), have established guidelines for the development of primary stroke centers (PSCs), which are hospitals that meet specific requirements for access to expertise, necessary hospital-based resources, and process criteria that are required to track appropriate use of rtPA.

One challenge to administering rtPA within $3 \mathrm{~h}$ is the fact that not every stroke patient can be seen by a neurologist in this period 
of time. In practice the window is much smaller, in that most patients arrive with not much more than 60 min left on the clock. While being seen by a neurologist is not strictly necessary, the application of the selection criteria for rtPA use and CT interpretation are sufficiently complex that access to experienced stroke physicians is of value (Webb et al., 1995; Mano, 2008). Previous research has indicated that designated stroke units and certifications along with specified stroke protocols can result in more appropriate rtPA use, increased adherence to post-rtPA protocols, and improved patient outcomes (Stroke Unit Trialists Collaboration, 1997; Goldstein et al., 2003; Douglas et al., 2005; Carr, 2010). Although rtPA can and is given in hospitals without PSC designation, the required designations and protocols can help ensure that the most effective care is given to stroke patients through standardization and the required use of stroke expertise. Although not proven, evidence suggests that PSC designation may improve the processes of care to allow for the optimal use of rtPA for stroke patients (Stradling et al., 2007).

One way to make stroke expertise available is through the use of telemedicine. The REACH MUSC (Remote Evaluation of Acute isCHemic Stroke) telemedicine stroke network in South Carolina was intended to increase access to stroke care in rural areas of the state. The same concept had previously been successfully implemented in Georgia through the Medical College of Georgia (REACH-MCG) and rural spoke hospitals (Switzer et al., 2009). Because of the expertise that may be required to administer rtPA, REACH allows small hospitals without on-site neurologists to provide this level of care to stroke patients in a cost effective way. The REACH MUSC system provides equipment, software, and neurology expertise to remote hospital sites via the internet to evaluate and treat acute strokes (Wang et al., 2004; Hess et al., 2005, 2006; Switzer et al., 2009). Using telemedicine to treat stroke may overcome barriers to high quality care that exist because of a shortage of stroke experts and the lack of PSCs in rural communities (Schwab et al., 2007; Capampangan et al., 2009; Demaerschalk et al., 2009; Schwamm et al., 2009a,b). Additionally, Carr et al. (2009) claim that, "rapid diagnosis and early intervention in acute illness or acutely decompensated chronic illness improves patient outcomes". In the stroke system of care model (SSCM), the American Heart Association (AHA) and the ASA have recommended the use of telemedicine to treat stroke acutely in "neurologically underserved areas" (Schwamm et al., 2009a,b, p. 2635). Telemedicine uses two-way real-time video conferencing with access to radiology images.

In light of this, the South Carolina legislature asked the Department of Health and Environmental Control to study stroke and make recommendations for the development of a stroke system of care (South Carolina Legislature ${ }^{1}$ ). Critical to the development of such a system are the established efforts to treat stroke acutely, including the use of rtPA. Like many states, South Carolina has attempted to do so with limited resources and has supported the further development of REACH MUSC.

The purpose of our study was to examine the impact of the establishment of REACH MUSC in South Carolina, specifically

${ }^{1}$ http://www.chronicdisease.org/files/public/CVHC\%20SC\%20General

\%20Assembly\%20Stroke\%20Legislation\%202009.pdf on access to acute stroke care in the state for the general population and specific segments of the population based on age, gender, race, ethnicity, education, urban/rural residence, poverty, and stroke mortality. Previous research conducted by the tri-state stroke network (TSSN) and the centers for disease control (CDC) has examined the impact and prevalence of stroke using a similar approach and found that there is limited access to rtPA treatment in the rural coastal plains that has many of the highest stroke death rates in the region. They provide an estimate of population access to rtPA treatment within $30 \mathrm{~min}$ to $1 \mathrm{~h}$ of stroke symptom onset in the tri-state region. Accordingly, only a half of the population of NC, SC, and GA lived within 30 min drive time to a PSC and rural residents had the least access (23\%; Khan et al., 2010).

\section{MATERIALS AND METHODS}

We studied U.S. Census data for South Carolina from the year 2000 to estimate the number of individuals who have access to stroke center care via a PSC or through REACH MUSC. We consider this care to include the possible treatment with rtPA, which has been shown to be more likely given in a designated stroke center with selective triage (Gropen et al., 2006). Expert stroke care is defined as a PSC or a hospital with a REACH MUSC enabled emergency department. We also account for Baptist Easley Hospital, which has a telemedicine relationship with Greenville Hospital Center similar to REACH MUSC.

To assess the access to stroke care in South Carolina, we used a geographic information systems (GIS) to calculate the number of South Carolinians that could be reasonably expected based on typical weather and road conditions to arrive at a stroke prepared or PSC hospital within 30 or $60 \mathrm{~min}$. Previous research has utilized these time periods as representing timely access to emergency care as allowing for "timely intervention of critical diseases" (Carr et al., 2009). We determined the number and percentage of South Carolinians who live within a 30 or 60 min drive to a PSC or a REACH MUSC hospital. These estimates were calculated with and without the REACH MUSC hospitals. None of the REACH MUSC sites were PSCs at the time of the analysis. Drive time service areas were calculated using ESRIs ${ }^{\circledR}$ Network Analyst Extension and StreetMap for ArcMap software. The analysis was conducted in two ways. This analysis computed the total population served by either a PSC or REACH MUSC hospital in October of 2010. To ensure that individuals were not counted twice as in the case of a person living within 30 or $60 \mathrm{~min}$ of more than one such hospital, we controlled for service area overlap.

We also assessed the contribution of REACH MUSC to access to expert stroke care for groups that have faced disparities in care. We examined the breakdown of South Carolinians within 30 or $60 \mathrm{~min}$ of a PSC or REACH MUSC hospital as it relates to individual age, gender, race, ethnicity, education, urban/rural residence, poverty, and stroke mortality in the county where the individuals lived. The data for this analysis came from the 2000 Census population totals for Census Tracts in South Carolina.

\section{RESULTS}

There were four Primary Stroke Centers in South Carolina during the time period of interest. The South Carolina REACH MUSC program began in May 2008 with two hospitals and has since 
grown to include 15 total hospitals. REACH MUSC hospitals include Georgetown Memorial Hospital, Grand Strand Regional Medical Center, Marion County Medical Center, McLeod Regional Medical Center, Waccamaw Community Hospital, Williamsburg Regional Hospital, Coastal Carolina, Piedmont, Kershaw, Self Regional, Loris, Loris-Seacoast, and McLeod-Dillon.

These hospitals have been selected as REACH MUSC spokes based on their geographic location, lack of stroke center status, desire to collaborate with MUSC and serving as an access point to South Carolinians who maybe having strokes as well as having the required access to $24 \mathrm{~h}$ intravenous pharmacy and CT scanning.

Without REACH MUSC in South Carolina, 975,722 (24\%) of South Carolinians lived within $30 \mathrm{~min}$ of a PSC; $38 \%$ or $1,517,467$ South Carolinians lived within $60 \mathrm{~min}$ of a PSC. The addition of the REACH MUSC hospitals has increased the number of South Carolinians with access to sites equipped to use of rtPA within $30 \mathrm{~min}$ to $1,725,379$ (43\%), which represents a $19 \%$ increase in the number of people with access. Furthermore, REACH MUSC doubled access for South Carolinians within $60 \mathrm{~min}$ of a stroke center or spoke hospital increasing the number to 3,059,919 (76\%).
These analyses and corresponding maps can be found in Figure 1, Tables 1 and 2.

REACH MUSC provided a disproportionate increase in access for certain groups that have been shown to face disparities in care. The addition of the REACH MUSC system increased the percentage of younger ( $<40$ years), African American, and rural South Carolinians within $30 \mathrm{~min}$ of a stroke center by 19,20 , and $20 \%$ respectively. When considering the 60 -min time window, access to stroke care through REACH MUSC increased the number of younger, African American, and rural South Carolinians within 60 min of PSC care by 39,46 , and $40 \%$ respectively. The access to PSC care or equivalent is also notable with an increase of $21 \%$ for those living in a county with poverty within $30 \mathrm{~min}$ of care and $41 \%$ for those living in a county with poverty within 60 min of care.

\section{DISCUSSION}

This study describes an important finding related to stroke care. The use of telemedicine can increase access for vulnerable populations who may seek emergency stroke care in small hospitals without PSC designation. In doing so, the REACH MUSC

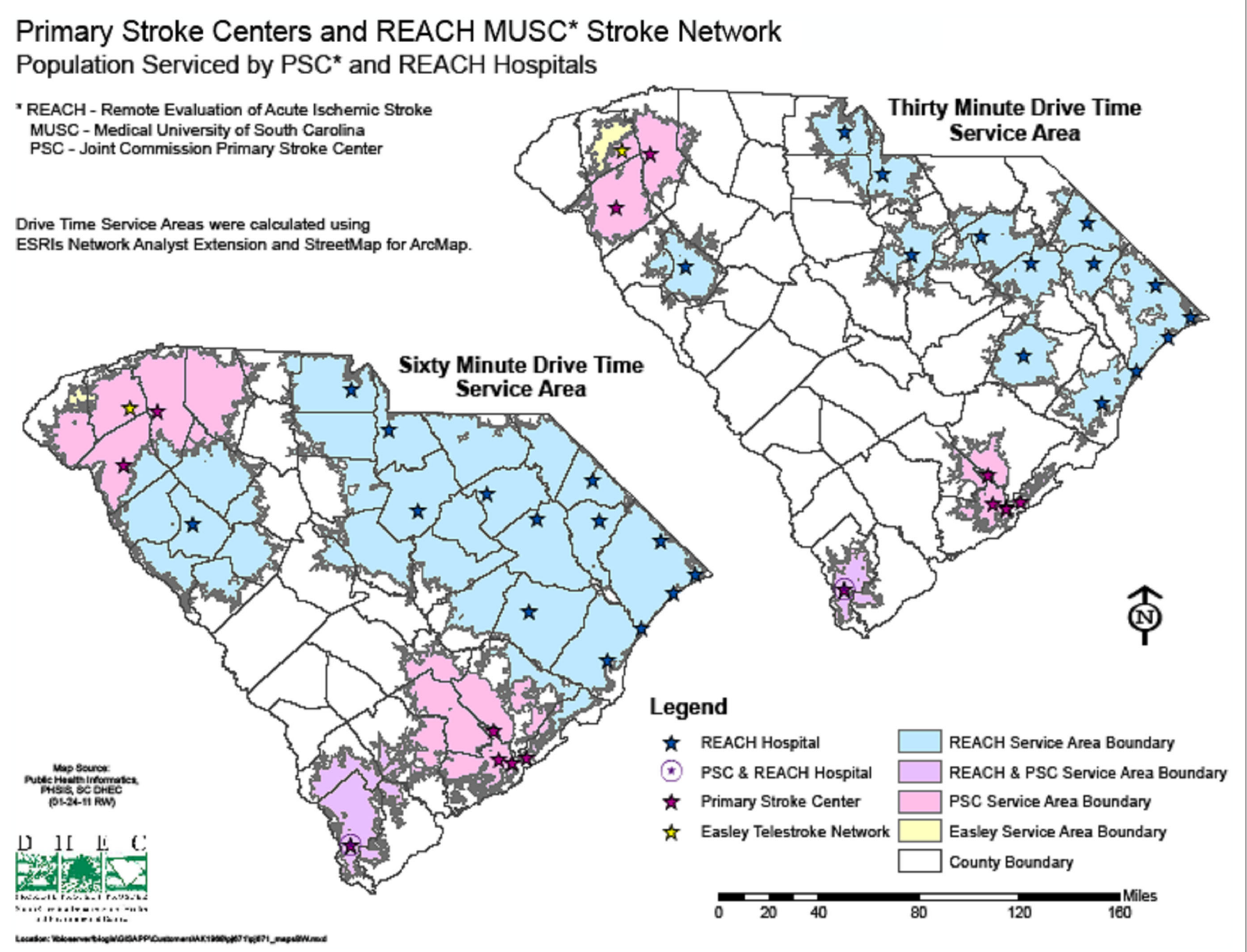

FIGURE 1 | Map of access to expert stroke care. 
Table 1 | Percentage of SC population within $30 \mathrm{~min}$ of expert stroke care.

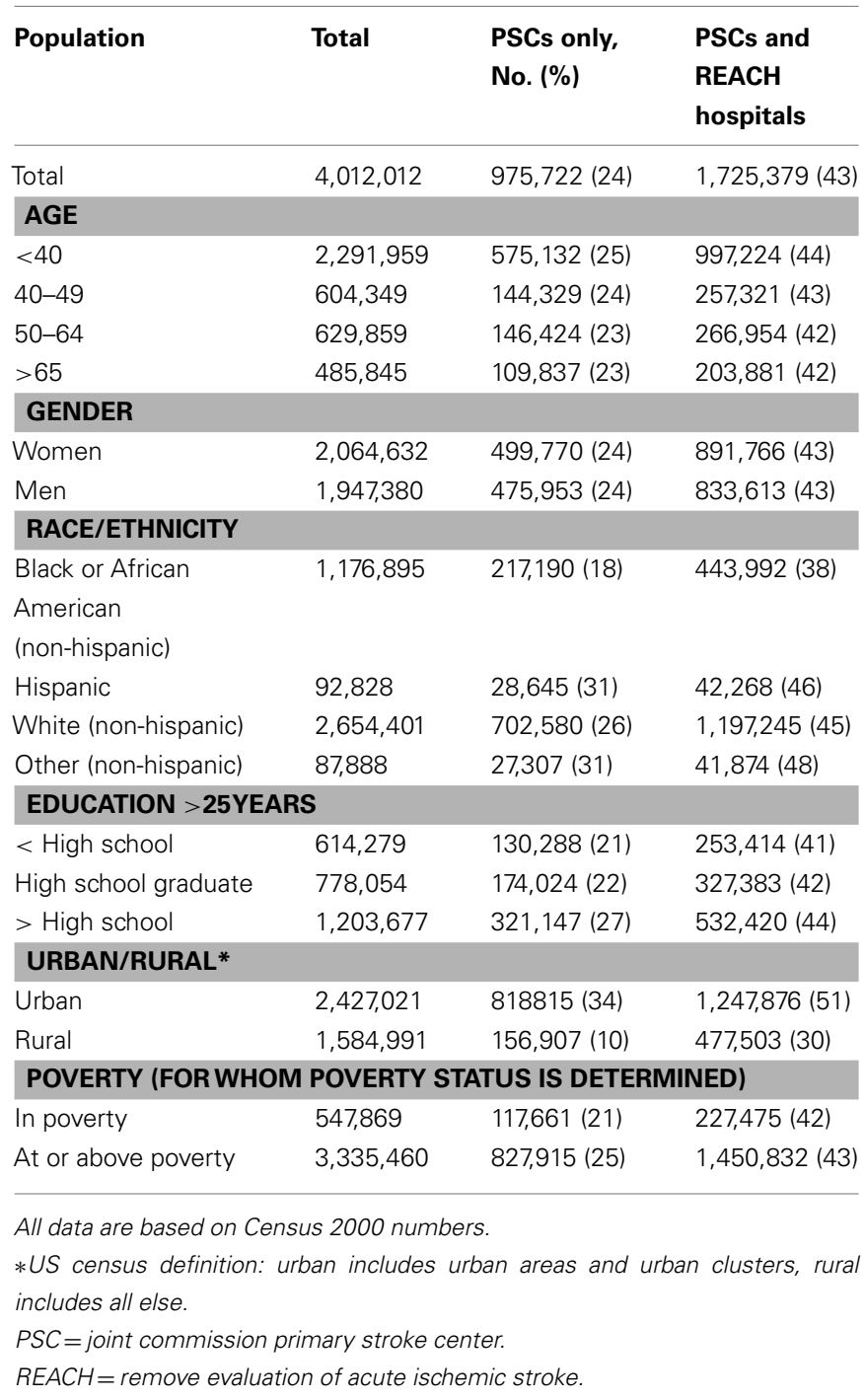

system has increased access to standardized stroke care and specific evidence based protocols for many thousands of South Carolinians in the eastern part of the state REACH MUSC was developed and launched very quickly during the period from August to December 2008, and because of it rtPA is being used in South Carolina through telemedicine. REACH MUSC provided hundreds of consultations at 15 spoke hospitals and has also led to the transfer to higher level care for patients as appropriate that might not have occurred prior to REACH MUSC. The large increases in access to expert stroke care for South Carolinians demonstrate the potential impact that the use of telemedicine may have in a geographic area. Furthermore, given that some PSCs may not have immediate on-site access to stroke expertise (up to $20 \mathrm{~min}$ in PSCs versus immediate access to CT interpretation through telemedicine), our study may underestimate the impact of telemedicine to treat AIS, which provides immediate consultation.
Table 2 | Percentage of SC population within $60 \mathrm{~min}$ of expert stroke care.

\begin{tabular}{|c|c|c|c|}
\hline Population & Total & $\begin{array}{l}\text { PSCs only, } \\
\text { No. (\%) }\end{array}$ & $\begin{array}{l}\text { PSCs and } \\
\text { REACH } \\
\text { hospitals }\end{array}$ \\
\hline Total & $4,012,012$ & $1,517,467(38)$ & $3,059,919(76)$ \\
\hline \multicolumn{4}{|l|}{ AGE } \\
\hline$<40$ & $2,291,959$ & $880,225(38)$ & $1,765,829(77)$ \\
\hline $40-49$ & 604,349 & $225,391(37)$ & $459,339(76)$ \\
\hline $50-64$ & 629,859 & $233,870(37)$ & $472,912(75)$ \\
\hline$>65$ & 485,845 & $177,982(37)$ & $361,840(74)$ \\
\hline \multicolumn{4}{|l|}{ GENDER } \\
\hline Women & $2,064,632$ & $777,008(38)$ & $1,577,625(76)$ \\
\hline Men & $1,947,380$ & 740,459 (38) & $1,482,294(76)$ \\
\hline \multicolumn{4}{|l|}{ RACE/ETHNICITY } \\
\hline \multicolumn{4}{|l|}{$\begin{array}{l}\text { American } \\
\text { (non-hispanic) }\end{array}$} \\
\hline Hispanic & 92,828 & $40,304(43)$ & $70,369(76)$ \\
\hline White (non-hispanic) & $2,654,401$ & $1,090,706(41)$ & $2,027,180(76)$ \\
\hline Other (non-hispanic) & 87,888 & $38,951(44)$ & $72,306(82)$ \\
\hline \multicolumn{4}{|c|}{ EDUCATION > 25YEARS } \\
\hline$<$ High school & 614,279 & $227,973(37)$ & $468,816(76)$ \\
\hline High school graduate & 778,054 & $286,499(37)$ & $587,586(76)$ \\
\hline$>$ High school & $1,203,677$ & $463,990(39)$ & $914,653(76)$ \\
\hline \multicolumn{4}{|l|}{ URBAN/RURAL* } \\
\hline Urban & $2,427,021$ & $1,068,151(44)$ & $1,981,252(82)$ \\
\hline Rural & $1,584,991$ & $449,316(28)$ & $1,078,667(68)$ \\
\hline \multicolumn{4}{|c|}{ POVERTY (FOR WHOM POVERTY STATUS IS DETERMINED) } \\
\hline In poverty & 547,869 & $190,469(35)$ & $416,091(76)$ \\
\hline At or above poverty & $3,335,460$ & $1,280,438(38)$ & $2,541,431(76)$ \\
\hline
\end{tabular}

All data are based on Census 2000 numbers.

* US Census definition: urban includes urban areas and urban clusters, rural includes all else.

$P S C=$ joint commission primary stroke center.

$\mathrm{REACH}=$ remove evaluation of acute ischemic stroke.

Attaining and maintaining PSC designation status is complex and costly, especially for smaller hospitals (Smith et al., 2008). With limited financial and human resources, REACH MUSC has sought to increase patient access to stroke expertise. The establishment of the REACH MUSC system has increased access to stroke care expertise within 30 and $60 \mathrm{~min}$ drive time for many South Carolinians. This differential has been especially noteworthy for African Americans' access to stroke care. We sought to further categorize access related to disparities in race, gender, poverty, education, urban/rural residence, and stroke mortality because previous research has indicated there are relevant disparities in the incidence and treatment of stroke (Lackland et al., 1998; Ellis et al., 2008). Because of the health disparities that exist in the incidence, diagnosis, and treatment of stroke related to race, age, gender, and geographic location, improvements must be made to increase access to standardized care for stroke patients in an equitable way. The REACH MUSC network can allow spoke hospitals 
to feel comfortable in giving rtPA for better patient outcomes by using specific evidence based protocols for care.

Our study does have limitations. The study is based on 2000 census data but we are not aware of major demographic changes in the last decade that would undermine the importance of our findings. Another limitation of our study is the fact that we only measure access to expert stroke care. While we do not imply that access always equals treatment, we recognize that having access to expert stroke care is a necessary precursor to treatment. A third limitation is that patients, even with access within 30 and $60 \mathrm{~min}$ may not arrive to the appropriate hospital in time to allow for diagnosis and treatment. Thus, we cannot conclude nor infer the number of patients with access who will be treated with rtPA.

Since healthcare resources and expertise may be limited in smaller hospitals and rural areas, it is important for organizations

\section{REFERENCES}

Alberts, M., Hademenos, G., Latchaw, R., Jagoda, A., Marler, J., Mayberg, M., Starke, R., Todd, H., Viste, K., Girgus, M., Shepard, T., Emr, M., Shwayder, P., and Walker, M. (2000). Recommendations for the Establishment of Primary Stroke Centers. J. Am. Med. Assoc. 283, 3102-3129.

Capampangan, D. J., Wellik, K. E., Bobrow, B. J., Aguilar, M. I., Ingall, T. J., Kiernan, T., Wingerchuk, D. M., and Memaerschalk, M. B. (2009). Telemedicine versus telephone for remote emergency stroke consultations: a critically appraised topic. Neurologist 15, 163-166.

Carr, B. G. (2010). Half of Americans live more than an hour away from lifesaving stroke care. Presented at the American Stroke Association International Stroke Conference, San Antonio. Available at: http://www.physorg.com/news 186236478.html [accessed February 24, 2010].

Carr, B. G., Branas, C. C., Metlay, J. P., Sullivan, A. F., and Camargo, C. A. (2009). Access to emergency care in the United States. Ann. Emerg. Med. 54, 261-269.

Demaerschalk, B. M., Miley, M. L., Kiernan, T. J., Bobrow, B. J., Corday, D. A., Wellik, K. E., Aguilar, M. I., Ingall, T. J., Dodick, D. W., Brazdyz, K., Koch, T. C., Ward, M. P., and Richemont, P. C. (2009). Stroke telemedicine. Mayo Clin. Proc. 84, 53-64.

Douglas, V. C., Tong, D. C., Gillum, L. A., Zhao, S., Brass, L. M., Dostal, J., and Johnston, S. C. (2005). Do the brain attack coalition's criteria for stroke centers improve care for ischemic stroke? Neurology 64, 422-427.

Ellis, C., Breland, H. L., and Egede, L. E. (2008). Racial/ethnic differences in the utilization of post-stroke rehabilitation services: a systematic review. Ethn. Dis. 18, 365-372.

Goldstein, L. B., Matchar, D. B., HoffLindquist, J., Samsa, G. P., and Horner, R. D. (2003). VA Stoke Study: neurologist care is associated with increased testing but improved outcomes. Neurology 61, 792-796.

Gropen, T. I., Gagliano, P. J., Blake, C. A., Sacco, R. L., Kwiatkowski, T., Richmond, N. J., Leifer, D., Libman, R., Azhar, S., Daley, M. B., and NYSDOH Stroke Center Designation Project Workgroup. (2006). Quality improvement in acute stroke: the New York State Stroke Center Designation Project. Neurology 68, 88-93.

Hacke, W., Kaste, M., Bluhmki, E., Brozman, M., Dávalos, A., Guidetti, D., Larrue, V., Lees, K. R., Medeghri, Z., Machnig, T., Schneider, D., von Kummer, R., Wahlgren, N., Toni, D., and for the ECASS Investigators. (2008). Thrombolysis with alteplase 3 to 4.5 hours after acute ischemic stroke. N. Engl. J. Med. 359, 1317-1329. Nichols, F. T., Hall, C. E., and Adams, R. J. (2006). Telestroke: extending stroke expertise into under served areas. Lancet Neurol. 5, 275-278. S., Pardue, C., Waller, J. L., Gross, H., Nichols, F., Hall, C., and Adams, R. J. (2005). REACH: clinical feasibility of a rural telestroke network. Stroke 36, 2018-2020.

Hoody, D., Hanson, S., Carter, D., and Zink, T. (2008). Implementing a stroke system of care in a rural hospital: a case report from Granite Falls. Minn. Med. 91, 37-40.

Khan, J. A., Casper, M., Asimos, A. W., Clarkson, L., Enright, D., Fehrs, L. J., George, M., Heidari, K., Huston,
Hess, D. C., Wang, S., Gross, H.,

Hess, D. C., Wang, S., Hamilton, W., Lee,

to explore relationships and mechanisms of cooperation with larger, advanced organizations with greater resources and expertise. The REACH MUSC system has allowed many more South Carolinians to have access to PSC care through the use of telemedicine. By connecting stroke experts at MUSC to patients at smaller community hospitals, the access to high quality care has increased. The rapid and substantial shift in access, documented in this paper, could only be accomplished by telemedicine.

\section{ACKNOWLEDGMENTS}

We would like to acknowledge the Southeastern Virtual Institute for Health Equity and Wellness (SE VIEW) funded by the Department of Defense and are grateful for their program support of The Stroke and Stroke Risk Reduction Initiative at MUSC.

S. L., Mettam, L., and Williams, I. (2010). Geographic and sociodemographic disparities in drive times to certified stroke centers in the tristate stroke network region - North Carolina, South Carolina, and Georgia. Fam. Community Health 8, A79.

Kleindorfer, D., Kissela, B., Schneider, A., Woo, D., Khoury, J., Miller, R., Alwell, K., Gebel, J., Szaflarski, J., Pancioli, A., Jauch, E., Moomaw, C., Shukla, R., Broderick, J. P., and Neuroscience Institute. (2004). Eligibility for recombinant tissue plasminogen activator in acute ischemic stroke: a population-based study. Stroke 35, e27-e29.

Kleindorfer, D., Xu, Y., Moomaw, C. J., Khatri, P., Adeoye, O., and Hornung, R. (2009). US geographic distribution of rtPA utilization by hospital for acute ischemic stroke. Stroke 40, 3580-3584.

Lackland, D. T., Bachman, D. L., Carter, T. D., Barker, D. L., Timms, S., and Kohli, H. (1998). The geographic variation in stroke incidence in two areas of Southeastern stroke belt: the Anderson and Pee Dee stroke study. Stroke 29, 2061-2068.

Mano, E. (2008). Safety issues and concerns for the neurological patient in the emergency department. Neurocrit. Care 9, 259-264.

Meschia, J. F. (2009). Camera in the emergency department: the evolution of stroke telemedicine. Mayo Clin. Proc. 84, 3-4.

O’Fallon, W. M., Asplund, K., Goldfrank, L. R., Hertzberg, V. S., Ingall, T. J., and Louis, T. A. (2004). Report of the tPA Review Committee. The National Institute of Neurological Disorders and Stroke.

Saposnik, G., Fang, J., O’Donnell, M., Hachinski, V., Kapral, M. K., and Hill, M. D. (2008). Escalating levels of access to in-hospital care and stroke mortality. Stroke 39, 2522-2530.

Schwab, S., Vatankhah, B., Kukla, C., Hauchwitz, M., Bodgahn, U., Furst, A., Audebert, H. J., and Horn, M. (2007). Long-term outcome after thrombolysis in telemedicine stroke care. Neurology 69, 898-903.

Schwamm, L. H., Holloway, R. G., Amarenco, P., Audebert, H. J., Bakas, T. M, Chumbler, N. R., Handschu, R., Jauch, E. C., Knight, W. A. IV, Levine, S. R., Mayberg, M., Meyer, B. C., Meyers, P. M., Skalabrin, E., and Weschler, L. R. (2009a). A review of the evidence for the use of telemedicine within stroke systems of care: a scientific statement from the American Heart Association/American Stroke Association. Stroke 40, 2616-2634.

Schwamm, L. H., Audebert, H. J., Amarenco, P., Chumbler, N. R., Frankel, M. R., George, M. G., Goerlick, P. B., Horton, K. B., Kaste, M., Lackland, D. T., Levine, S. R., Meyer, B. C., Meyers, P. M., Patterson, V., Stranne, S. K., and White, C. J. (2009b). Recommendations for the implementation of telemedicine within stroke systems of care: a policy statement from the American Heart Association. Stroke 40, 2635-2660.

Shrira, I., Christenfeld, N., and Howard, G. (2008). Exposure to US Stroke Buckle as a risk factor for cerebrovascular mortality. Neuroepidemiology 30, 229-233.

Smith, E. E., Dreyer, P., Prvu-Bettger, J., Abdullah, A. R., Palmeri, G., Goyette, L., McElligott, C., and Schwamm, L. H. (2008). Stroke center designation can be achieved by small hospitals, the Massachusetts experience. Crit. Pathw. Cardiol. 7, 173-177.

Stradling, D., Yu, W., Langdorf, J. L., Tsai, F., Kostanian, V., Hasso, A. N., 
Welbourne, S. J., Schooley, Y., Fisher, M. J., and Cramer, S. C. (2007). Stroke care delivery before vs. after JCAHO stroke center certification. Neurology 68, 469-470.

Stroke Unit Trialists Collaboration. (1997). How do stroke units improve patient outcomes? A collaborative systematic review of the randomized trials. Stroke 28, 21392144.

Switzer, J. A., Hall, C., Gross, H., Waller, J., Nichols, F. T., Wang, S., Adams, R. J., and Hess, D. C. (2009). A webbased telestroke system facilitates rapid treatment of acute ischemic stroke patients in rural emergency departments. J. Emerg. Med. 36, 12-18.
Thom, T., Haase, N., Rosamond, W., Howard, V. J., Rumsfield, J., Manolio, T., Zheng, Z. J., Flegal, K., O’Donnell, C., Kittner, S., Lloyd-Jones, D., Goff, D. C. Jr., Hong, Y., Adams, R., Friday, G., Furie, K., Gorelick, P., Kissela, B., Marler, J., Meigs, J., Roger, V., Sidney, S., Sorlie, P., Steinberger, J., Wasserthiel-Smoller, S., Wilson, M., and Wolf, P. (2006). Heart disease and stroke statistics 2006 update: a report from the American Heart Association Statistics Committee and Stroke Statistics Subcomittee. Circulation 113, 85-151.

Wang, S., Gross, H., Less, S. B., Pardue, C., Waller, J., Nichols, F. T.
III, Adams, R. J., and Hess, D. C. (2004). Remote evaluation of acute ischemic stroke in rural community hospitals in Georgia. Stroke 35, 1763-1768.

Webb, D. J., Fayad, P. B., Wilbur, C., Thomas, A., and Brass, L. M. (1995). Effects of a specialized team on stroke care. The first two years of the Yale Stroke Program. Stroke 26, 1353-1357.

Conflict of Interest Statement: The authors declare that the research was conducted in the absence of any commercial or financial relationships that could be construed as a potential conflict of interest.
Received: 19 October 2011; accepted: 06 March 2012; published online: 21 March 2012.

Citation: Kazley AS, Wilkerson RC, Jauch E and Adams RJ (2012) Access to expert stroke care with telemedicine: REACH MUSC. Front. Neur. 3:44. doi: 10.3389/fneur.2012.00044

This article was submitted to Frontiers in Teleneurology, a specialty of Frontiers in Neurology.

Copyright (c) 2012 Kazley, Wilkerson, Jauch and Adams. This is an open-access article distributed under the terms of the Creative Commons Attribution Non Commercial License, which permits noncommercial use, distribution, and reproduction in other forums, provided the original authors and source are credited. 